\title{
Author Correction to: A simulation-based study on the effect of package parameters on the random vibration behavior of electronic packages
}

\section{Mohammad A. Gharaibeh ${ }^{\mathrm{a}}(1)$}

Department of Mechanical Engineering, Faculty of Engineering, The Hashemite University, P.O. Box 330127, Zarqa 13133, Jordan

(C) The Author(s), under exclusive licence to Società Italiana di Fisica and Springer-Verlag GmbH Germany, part of Springer Nature 2022

Author Correction to: Eur. Phys. J. Plus (2021) 136:1132

https://doi.org/10.1140/epjp/s13360-021-02102-7

In this article, the affiliation details were incorrectly given as 'Mechanical Engineering Department, The Hashemite University, Zarqa 13133, Jordan' but should have been 'Department of Mechanical Engineering, Faculty of Engineering, The Hashemite University, P.O. Box 330127, Zarqa 13133, Jordan.'

The original article can be found online at https://doi.org/10.1140/epjp/s13360-021-02102-7.

a e-mail: mohammada_fa@hu.edu.jo (corresponding author) 